\title{
Public's attitudes towards community pharmacy in Qatar: a pilot study
}

\author{
This article was published in the following Dove Press journal: \\ Patient Preference and Adherence \\ 16 August 2011 \\ Number of times this article has been viewed
}

\author{
Maguy Saffouh El Hajj \\ Samah Salem \\ Hend Mansoor \\ College of Pharmacy, \\ Qatar University, Doha, Qatar
}

Correspondence: Maguy El Hajj College of Pharmacy, Qatar University,

Doha 2713, Qatar

Tel +97444035577

Fax +974 4403555

Email maguyh@qu.edu.qa
Objectives: To assess the public's attitudes towards the community pharmacist's role in Qatar, to investigate the public's use of community pharmacy, and to determine the public's views of and satisfaction with community pharmacy services currently provided in Qatar.

Materials and methods: Three community pharmacies in Qatar were randomly selected as study sites. Patients 16 years of age and over who were able to communicate in English or Arabic were randomly approached and anonymously interviewed using a multipart pretested survey.

Results: Over 5 weeks, 58 patients were interviewed (60\% response rate). A total of $45 \%$ of respondents perceived community pharmacists as having a good balance between health and business matters. The physician was considered the first person to contact to answer drug-related questions by $50 \%$ of respondents. Most patients agreed that the community pharmacist should provide them with the medication directions of use (93\%) and advise them about the treatment of minor ailments (79\%); however, more than $70 \%$ didn't expect the community pharmacist to monitor their health progress or to perform any health screening. Half of the participants (52\%) reported visiting the pharmacy at least monthly. The top factor that affected a patient's choice of any pharmacy was pharmacy location $(90 \%)$. When asked about their views about community pharmacy services in Qatar, only 37\% agreed that the pharmacist gave them sufficient time to discuss their problem and was knowledgeable enough to answer their questions.

Conclusion: This pilot study suggested that the public has a poor understanding of the community pharmacist's role in monitoring drug therapy, performing health screening, and providing drug information. Several issues of concern were raised including insufficient pharmacist-patient contact time and unsatisfactory pharmacist knowledge. To advance pharmacy practice in Qatar, efforts may be warranted to address identified issues and to promote the community pharmacist's role in drug therapy monitoring, drug information provision, and health screening.

Keywords: pharmacist, public, attitudes, Qatar

\section{Introduction}

Over the past four decades, the pharmacy profession has made considerable efforts to shift its focus from medication supply to patient care. Pharmacists have become increasingly interested in broadening their role beyond the product-oriented functions of dispensing and compounding of medications to the provision of cognitive pharmaceutical services, information, and pharmaceutical care. ${ }^{1}$ Pharmacists who adopt the pharmaceutical care approach can significantly contribute to the outcome of drug therapy and improve patient quality of life by tailoring their drug-related needs. ${ }^{2}$ Pharmacists in all practice settings, including community pharmacy, are increasingly 
encouraged to provide pharmaceutical care. Community pharmacists are in a distinctive position to identify, prevent, and resolve drug-related problems in ambulatory patients, and data suggests that community-based pharmacy services can improve health outcomes. ${ }^{3,4}$ The pharmaceutical care framework assumes a patient-pharmacist professional relationship that is based upon caring, trust, communication, cooperation, and mutual decision making in which the pharmacist works very closely with the patient to promote health, to prevent disease, and to insure that drug therapy is safe and effective. ${ }^{5}$ Because of this close relationship, the successful implementation of the pharmaceutical care framework in community pharmacies requires that patients appropriately understand the pharmacist's professional role especially with respect to consultation with patients, monitoring the appropriateness of drug regimens, and other pharmaceutical care activities. Problems in pharmacist consultation can occur when patients and pharmacists have different expectations about the pharmacist's role and pharmacy services. One study has demonstrated that patients who have low expectations for consultation with a pharmacist receive less consultation than patients with higher expectations. In addition, if patients with low role orientations do receive any consultation they might not comply with it, severing the effects that pharmacy services can have on patient outcomes. ${ }^{6}$ Therefore, the advancement of community pharmacy practice through the adoption of the pharmaceutical care model needs understanding of patients' perceptions of the pharmacist's role as well as of their utilization and views of community pharmacy services.

Qatar is an Arabic country of approximately 1.4 million residents (2009 estimate) and $11,000 \mathrm{~km}^{2}$, located in the Gulf Region of the Middle East. Qatar has transformed itself from a poor British state into an independent state with important oil and natural gas revenues. The majority of the residents of Qatar are expatriates who were attracted to this country by the economic and professional opportunities associated with its growth. ${ }^{7}$ One sector that is also seeing remarkable growth is the health care sector. The majority of health care facilities in this country are governmental facilities that offer services to citizens and residents. Outside governmental hospitals and clinics, patients can get their medications from over 140 private sector community pharmacies. More than 350 pharmacists practice in these pharmacies. Except for very few cognitive and patient-oriented activities performed, community pharmacists' duties are limited to dispensing of medications, and very little pharmacist-patient interaction occurs. ${ }^{8}$ Nevertheless, these community pharmacists are increasingly interested in defining a specific and well recognized vocation for themselves in today's health care system and in extending their role beyond the dispensary into a more active role of dealing with patients' drug-related problems. According to a recent study conducted by Qatar University (QU) College of Pharmacy, only $40 \%$ of surveyed community pharmacists were professionally satisfied. When asked how to best improve their satisfaction, dissatisfied pharmacists identified improvements to their professional role, advancement in their professional activities, and greater opportunities for development as important factors for satisfaction. ${ }^{9}$

A key factor in advancing pharmacy practice in community pharmacies in Qatar is the understanding of public needs and expectations. Knowledge about public utilization of, and views about, community pharmacy services can assist pharmacists in meeting customers' needs, in enhancing the quality of their services and improving customer satisfaction.

Greater customer satisfaction, in turn, can be translated into greater loyalty to particular pharmacies and can facilitate the provision of pharmaceutical care through better customer-pharmacist communication. ${ }^{10}$

Many studies have investigated public use of, and attitudes about, community pharmacy in Canada, Jordan, Malta, Saudi Arabia, and other countries. ${ }^{11-14}$ The main reason for using a particular pharmacy in Saudi Arabia was the presence of trusted and qualified pharmacists, while the most commonly offered reason in Jordan was the proximity of the pharmacy to the individual's home. ${ }^{12,14}$ More than $60 \%$ of customers in Malta and in Jordan stated that their primary reason for seeking pharmacist advice rather than physician was when the condition was not serious enough to visit the physician. ${ }^{12,13}$ Around half of Saudi customers believed that the pharmacist was more concerned with the business side of the profession than with its health side. ${ }^{14}$ In comparison, most Canadian customers considered pharmacists as health care professionals even if they practiced in retail settings. ${ }^{11}$

To our knowledge, there are no published reports assessing the public's attitudes towards the community pharmacist's role in Qatar. As well, information regarding the public's use and views of community pharmacy services is lacking in this country.

The objectives of this study were to assess public's attitudes towards the community pharmacist's role in Qatar, to investigate the public's use of community pharmacy, and to determine the public's views of and satisfaction with community pharmacy services currently provided in Qatar. 
We report here the results of a pilot study which was the first step of a nationwide project aimed at assessing public use of, and attitudes about, community pharmacy in Qatar.

\section{Material and methods}

Qatar's Supreme Council of Health lists more than 120 community pharmacies in Qatar. Three community pharmacies were randomly selected from the list (2.5\% sample rate). The study investigators contacted the selected pharmacies, explained to the pharmacists the study objectives, and assured them that the study would assess the public's general attitudes towards community pharmacy practice rather than their experience with particular pharmacies. Permission was obtained to approach patients when they entered the pharmacy to ask them to participate in the study. The investigators visited selected pharmacies on different days of the week and at different times of the day to encounter a wide cross section of the community. Members of the public who appeared to be over 16 years of age and able to communicate in English or Arabic were randomly approached, provided with the study objectives, assured about data confidentiality and anonymity, and requested to participate. Patients who offered oral consent were anonymously interviewed for 20 minutes in English or Arabic based on the patient's spoken language using a multipart pretested survey. Individuals who did not offer oral consent or were not able to answer the survey questions due to language barriers were excluded.

Data collection took place over a 5-week period during normal daytime business hours between October 2009 and November 2009. A convenience sample of around 60 patients (20 patients per study site) was selected.

The survey questionnaire was developed from similar studies done in the UK, Saudi Arabia, and Jordan, with some modification ${ }^{12,14,15}$ (see Appendix 1). Before its implementation, the survey was translated into Arabic and pretested in both languages in a small sample of the general public (10 patients) for clarity, relevance, acceptability, and time to completion. Refinements were made to the survey accordingly.

The survey consisted of 20 open- and close-ended questions that addressed patients' sociodemographic characteristics, their attitudes and expectations about the community pharmacist's role, their use of community pharmacy, and their views of and satisfaction with community pharmacy services currently provided in Qatar. Sociodemographic characteristics included age, gender, marital status, country of origin, highest level of education, and occupation (Table 1). To assess patients' attitudes and expectations about the
Table I Patient survey-respondent sociodemographic characteristics

\begin{tabular}{|c|c|}
\hline Characteristic & Frequency (\%) \\
\hline \multicolumn{2}{|l|}{ Gender $(N=58)$} \\
\hline Female & $32(55)$ \\
\hline \multicolumn{2}{|l|}{ Age $(N=52)$} \\
\hline$<30$ years & $22(42)$ \\
\hline $30-50$ years & $27(52)$ \\
\hline$>50$ years & $3(6)$ \\
\hline \multicolumn{2}{|l|}{ Marital status $(\mathrm{N}=58)$} \\
\hline Married & $38(66)$ \\
\hline \multicolumn{2}{|l|}{ Country of origin $(N=57)$} \\
\hline Qatar & $18(32)$ \\
\hline Bilad Al Sham ${ }^{\mathrm{a}}$ & $11(19)$ \\
\hline Africa $^{b}$ & II (19) \\
\hline Asia $^{c}$ & $8(14)$ \\
\hline Other GCC & $6(11)$ \\
\hline Other countries & $3(5)$ \\
\hline \multicolumn{2}{|l|}{ Highest level of education $(\mathrm{N}=57)$} \\
\hline Less than high school & $3(5)$ \\
\hline High school & $11(19)$ \\
\hline Technical or college degree & $13(23)$ \\
\hline Undergraduate degree & $7(12)$ \\
\hline Post-graduate degree & $23(4 I)$ \\
\hline \multicolumn{2}{|l|}{ Occupation $(\mathrm{N}=57)$} \\
\hline $\begin{array}{l}\text { Social sciences, education, government service, } \\
\text { and religion }\end{array}$ & $14(24)$ \\
\hline Business, finance, and administration & $13(23)$ \\
\hline Housewife & $8(\mid 4)$ \\
\hline Student & $7(12)$ \\
\hline Natural and applied sciences & $4(7)$ \\
\hline Health sciences & $3(5)$ \\
\hline Sales and service & $3(5)$ \\
\hline Art, culture, recreation, and sport & $2(4)$ \\
\hline Trade, transport, and equipment operators & $2(4)$ \\
\hline Management & $\mathrm{I}(2)$ \\
\hline
\end{tabular}

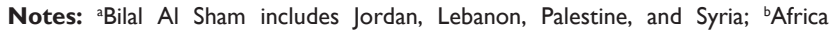
includes Egypt, Ghana, and Sudan; 'Asia includes India, Indonesia, and Philippines; ${ }^{ } \mathrm{GCC}$ includes Iraq, Oman, and Yemen.

Abbreviation: GCC, Gulf Cooperation Council Country.

community pharmacist's role, a 5-point Likert scale (strongly agree, agree, neutral, disagree, strongly disagree) was used to measure the extent to which patients agreed with statements related to the different community pharmacist's roles and responsibilities (Table 2). In addition, the patients were asked about (1) their view of the community pharmacist (Figure 1), (2) their first contact person in case of a drug-related question, (3) their reason for approaching the pharmacist before the physician, (4) the pharmacist qualities that they desire, and (5) the barriers that prevent them from asking pharmacists questions (Table 3). To evaluate their use of community pharmacy, the patients were inquired about (1) their reasons for visiting a community pharmacy (Table 4), (2) the factors that make them choose a particular pharmacy (Figure 2), 
Table 2 Patient expectations about the community pharmacist's role in Qatar

\begin{tabular}{|c|c|c|c|c|}
\hline \multirow{2}{*}{$\begin{array}{l}\text { Statement } \\
\text { I expect the community pharmacist to: }\end{array}$} & \multicolumn{3}{|l|}{ Frequency (\%) ${ }^{a}$} & \multirow{2}{*}{$\begin{array}{l}\text { Mean } \pm \text { SD } \\
(95 \% \mathrm{Cl})\end{array}$} \\
\hline & $\begin{array}{l}\text { Strongly agree } \\
\text { or agree }\end{array}$ & Neutral & $\begin{array}{l}\text { Strongly disagree } \\
\text { or disagree }\end{array}$ & \\
\hline \multicolumn{5}{|c|}{ What are your expectations about community pharmacist's role in Qatar? } \\
\hline $\begin{array}{l}\text { Initiate dialog with me or with my physician, } \\
\text { when necessary to obtain a sufficiently detailed } \\
\text { medication history }\end{array}$ & $31(53)$ & $4(7)$ & $23(40)$ & $\begin{array}{l}3.10 \pm 1.12 \\
(2.81-3.40)\end{array}$ \\
\hline Counsel me about my disease & $4 \mid(7 \mid)$ & I (2) & $16(27)$ & $\begin{array}{l}3.38 \pm 1.24 \\
(3.05-3.7)\end{array}$ \\
\hline $\begin{array}{l}\text { Counsel me about the main side effects of my } \\
\text { medications and how to avoid them and about } \\
\text { their potential interactions with other medicines }\end{array}$ & $44(76)$ & $0(0)$ & $14(24)$ & $\begin{array}{l}3.53 \pm 1.14 \\
(3.23-3.83)\end{array}$ \\
\hline Counsel me about the directions for use of medications & $54(93)$ & $0(0)$ & $4(7)$ & $\begin{array}{l}4.03 \pm 0.75 \\
(3.84-4.23)\end{array}$ \\
\hline Counsel me about the medications' action and indication & $28(48)$ & $7(12)$ & $23(40)$ & $\begin{array}{l}3.12 \pm 1.1 \\
(2.83-3.40)\end{array}$ \\
\hline $\begin{array}{l}\text { Monitor my health's progress to ensure the safe and } \\
\text { effective use of medications }\end{array}$ & $13(23)$ & $6(10)$ & $39(67)$ & $\begin{array}{l}2.50 \pm 1.06 \\
(2.22-2.78)\end{array}$ \\
\hline $\begin{array}{l}\text { Help me in selecting a home diagnostic, an } \\
\text { over-the-counter medication or a para-pharmaceutical } \\
\text { product, eg, baby care, hair products, cosmetics, etc }\end{array}$ & $38(65)$ & $4(7)$ & $16(28)$ & $\begin{array}{l}3.40 \pm 1.03 \\
(3.13-3.68)\end{array}$ \\
\hline Answer my drug-related questions & $51(88)$ & $4(7)$ & $3(5)$ & $\begin{array}{l}3.86 \pm 0.54 \\
(3.72-4.00)\end{array}$ \\
\hline $\begin{array}{l}\text { Counsel and advise me on the treatment of } \\
\text { minor ailments; for example, headache, heartburn, } \\
\text { constipation, muscle pain, minor skin problems etc }\end{array}$ & $46(79)$ & $4(7)$ & $8(14)$ & $\begin{array}{l}3.67 \pm 0.73 \\
(3.48-3.87)\end{array}$ \\
\hline $\begin{array}{l}\text { Check my prescriptions for accuracy in terms } \\
\text { of drug name and dose }\end{array}$ & $48(83)$ & $4(7)$ & $6(10)$ & $\begin{array}{l}3.78 \pm 0.70 \\
(3.59-3.96)\end{array}$ \\
\hline Label my medications & $43(74)$ & $2(3)$ & $13(23)$ & $\begin{array}{l}3.57 \pm 1.01 \\
(3.30-3.83)\end{array}$ \\
\hline $\begin{array}{l}\text { Perform proper screening and monitoring for } \\
\text { specific health conditions and diseases }\end{array}$ & $15(26)$ & $5(9)$ & $38(65)$ & $\begin{array}{l}2.5 \pm 1.04 \\
(2.22-2.78)\end{array}$ \\
\hline
\end{tabular}

Note: aResponses have been collapsed into a three-point scale: Agree, Neutral, and Disagree. Neutral implies "neither agree nor disagree".

Abbreviations: $\mathrm{Cl}$, confidence interval; $\mathrm{SD}$, standard deviation.

and (3) the frequency of their community pharmacy visits. To gauge their satisfaction level with current pharmacy services in Qatar, a 5-point Likert scale (strongly agree, agree, neutral, disagree, strongly disagree) was used to measure the extent to which the patients agreed with statements related to their interactions with Qatar's community pharmacists and to their perceptions of the pharmacists' accessibility and approachability (Table 5). Finally, seven possible services were listed, and the patients were asked to specify the services that they would like see provided in community pharmacies in Qatar (Figure 3).

Completed questionnaires were coded, reviewed for accuracy, entered into a SPSS Statistics version 17.0 (IBM Corporation, Somers, NY) database and analyzed using descriptive analysis. Categorical data were calculated as frequencies and percentages, and continuous data were calculated as means and standard deviations. Five-point Likert scale responses were collapsed into three general categories (agree, neutral, disagree), and mean scores and standard deviations were computed for each statement.

Incomplete surveys were included in the analysis, provided basic demographic information and a response to the particular question was provided. Accordingly, the denominator (ie, number of respondents) for each response may vary. To minimize any potential for bias and to protect participant confidentiality and anonymity, the survey was anonymously completed, ie, no participant identification information was collected. Collected data were retained in a password-protected database and maintained along with all related study documentation in a locked office at Qatar University College of Pharmacy.

\section{Results}

During the 5-week study period, 96 patients were approached and 58 patients answered the survey $(60 \%$ response rate). 


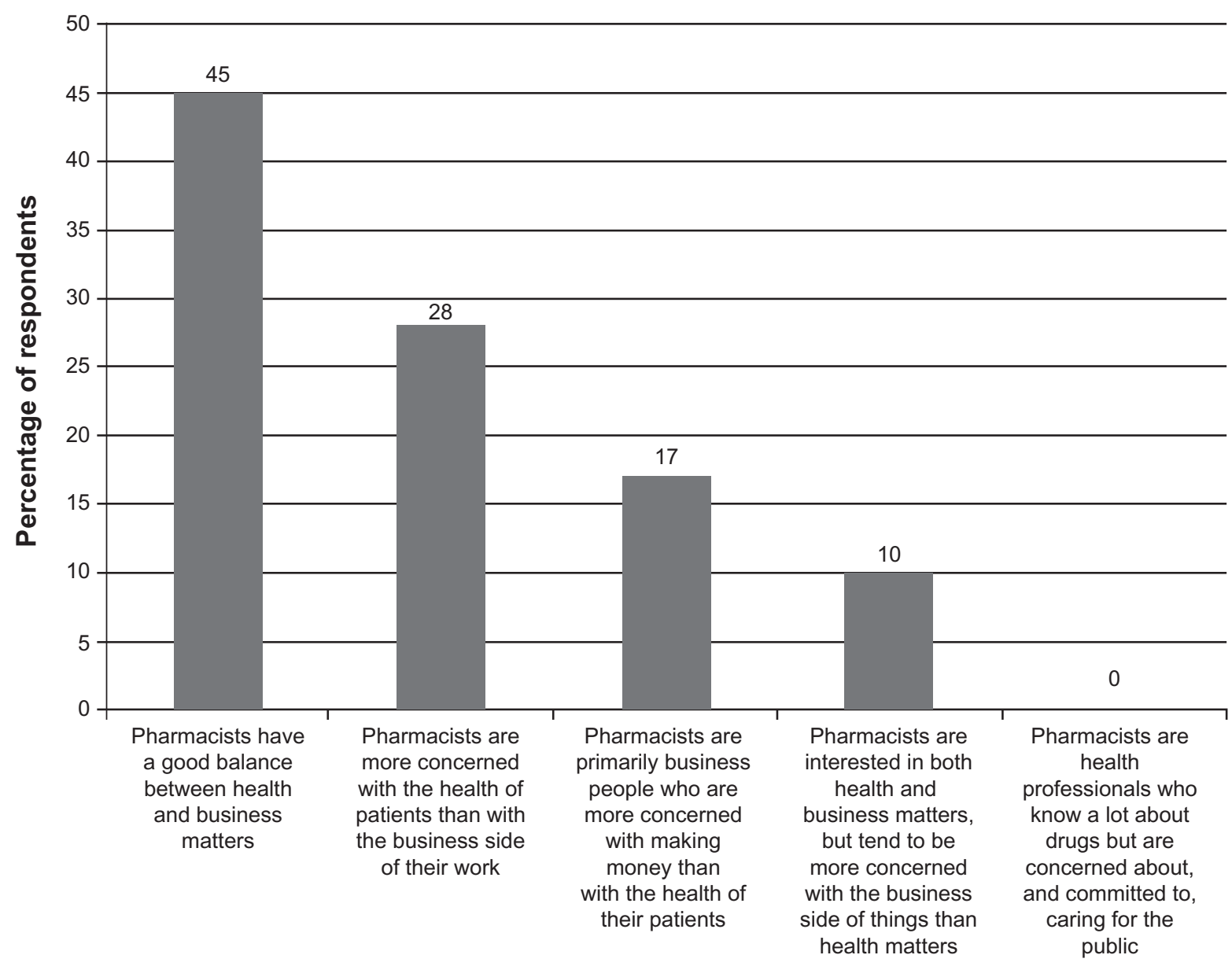

Figure I Patient survey-respondent view of community pharmacists.

\section{Patient survey-respondent sociodemographic characteristics}

The sociodemographic characteristics of respondents are summarized in Table 1. The mean age was 34 years, with a standard deviation of \pm 11 years, and the majority of respondents were females (55\%). Seventeen countries were represented, with 32\% coming from Qatar, followed by

Table 3 Patient perceived barriers for asking questions to community pharmacists

\begin{tabular}{ll}
\hline Perceived barrier & Frequency (\%) \\
\hline Lack of privacy in the pharmacy & $29(50)$ \\
Doctors are more trusted than pharmacists & $26(45)$ \\
Busyness of the pharmacist & $25(43)$ \\
Fear or intimidation of asking the pharmacist & $23(40)$ \\
Lack of awareness of the ability of the pharmacist & $23(40)$ \\
to answer drug- and disease-related questions & \\
Lack of pharmacist's knowledge to answer & $21(36)$ \\
drug- and disease-related questions & $16(28)$ \\
$\begin{array}{l}\text { Unavailability of the pharmacist to answer } \\
\text { my questions }\end{array}$ & \\
Rudeness of the pharmacist & $15(26)$ \\
\hline
\end{tabular}

Bilad Al Sham (19\%) and Africa (19\%). Fifty percent of respondents had at least a university degree.

\section{Patient survey-respondent attitudes and expectations about community pharmacists}

Figure 1 shows the patient view of the community pharmacist. Forty-five percent of respondents perceived community pharmacists as health care professionals who had a good balance

Table 4 Main reasons for visiting a community pharmacy

\begin{tabular}{ll}
\hline Main reason for visiting & Frequency (\%) \\
a community pharmacy & \\
\hline To obtain over-the-counter medications & $54(93)$ \\
To obtain prescription medications & $48(83)$ \\
To obtain para-pharmaceutical products & $38(66)$ \\
To obtain home diagnostics & $33(57)$ \\
To ask for pharmacist advice & $20(35)$ \\
To get general health information & $13(23)$ \\
To get first-aid information & $12(21)$ \\
\hline
\end{tabular}

Note: apara-pharmaceutical products include, for example, sunscreens, cosmetics, toiletries, hair care, and baby care products. 


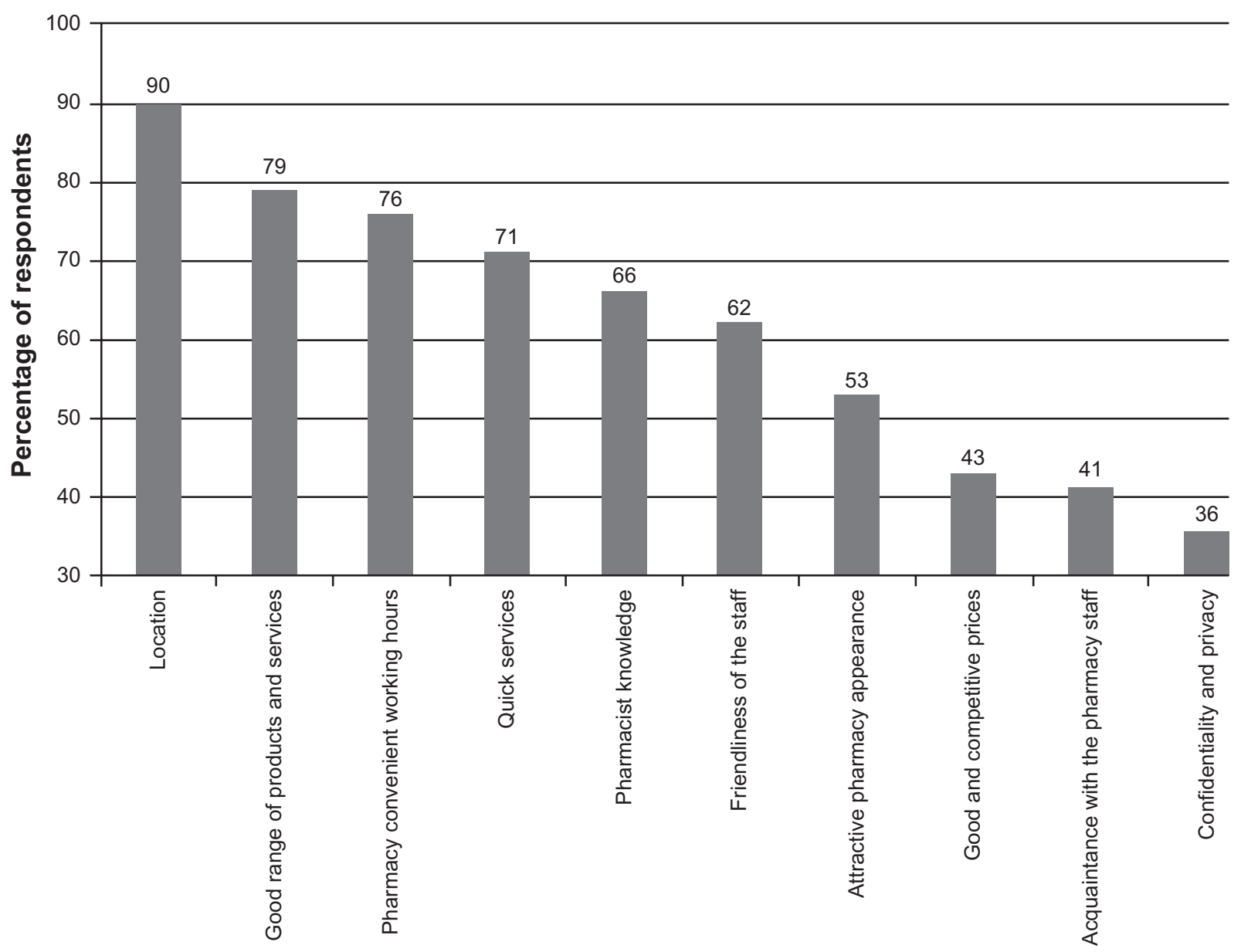

Figure 2 Factors influencing the choice of any particular pharmacy.

Table 5 Patient views of community pharmacy services currently provided in Qatar

\begin{tabular}{|c|c|c|c|c|}
\hline \multirow[t]{2}{*}{ Statement } & \multicolumn{3}{|l|}{ Frequency $(\%)^{a}$} & \multirow{2}{*}{$\begin{array}{l}\text { Mean } \pm \text { SD } \\
(95 \% \mathrm{CI})\end{array}$} \\
\hline & $\begin{array}{l}\text { Strongly agree } \\
\text { or agree }\end{array}$ & Neutral & $\begin{array}{l}\text { Strongly disagree } \\
\text { or disagree }\end{array}$ & \\
\hline \multicolumn{5}{|c|}{ What is your extent of agreement with the following statements? } \\
\hline $\begin{array}{l}\text { When I am in the pharmacy I feel totally at ease } \\
\text { about asking the pharmacist for advice }\end{array}$ & $23(45)$ & II (22) & $17(33)$ & $\begin{array}{l}3.25 \pm 1.02 \\
(2.97-3.54)\end{array}$ \\
\hline $\begin{array}{l}\text { When I am buying my prescription medications, the } \\
\text { pharmacist hands me my prescriptions, provides me } \\
\text { with thorough medication counseling, and encourages } \\
\text { me to ask questions }\end{array}$ & $17(34)$ & II (22) & $22(44)$ & $\begin{array}{l}2.98 \pm 1.08 \\
(2.67-3.29)\end{array}$ \\
\hline $\begin{array}{l}\text { When I am buying my prescription medications, } \\
\text { privacy concerning my prescriptions is maintained } \\
\text { by the pharmacist }\end{array}$ & $17(35)$ & $13(27)$ & $19(39)$ & $\begin{array}{l}3.02 \pm 0.97 \\
(2.74-3.30)\end{array}$ \\
\hline $\begin{array}{l}\text { When I go to the pharmacy with a problem the } \\
\text { pharmacist gives me enough time to discuss my } \\
\text { problem and listens to me carefully }\end{array}$ & $18(37)$ & $12(24)$ & $19(39)$ & $\begin{array}{l}3.02 \pm 1.01 \\
(2.73-3.31)\end{array}$ \\
\hline $\begin{array}{l}\text { When I go to the pharmacy to ask any drug-related } \\
\text { question, the pharmacist is knowledgeable enough } \\
\text { and always ready to answer my questions }\end{array}$ & $18(37)$ & $6(13)$ & $24(50)$ & $\begin{array}{l}2.89 \pm I . I \\
(2.58-3.21)\end{array}$ \\
\hline
\end{tabular}

Note: 'Responses have been collapsed into a three-point scale: Agree, Neutral, and Disagree. Neutral implies "neither agree nor disagree".

Abbreviations: $\mathrm{Cl}$, confidence interval; $\mathrm{SD}$, standard deviation. 


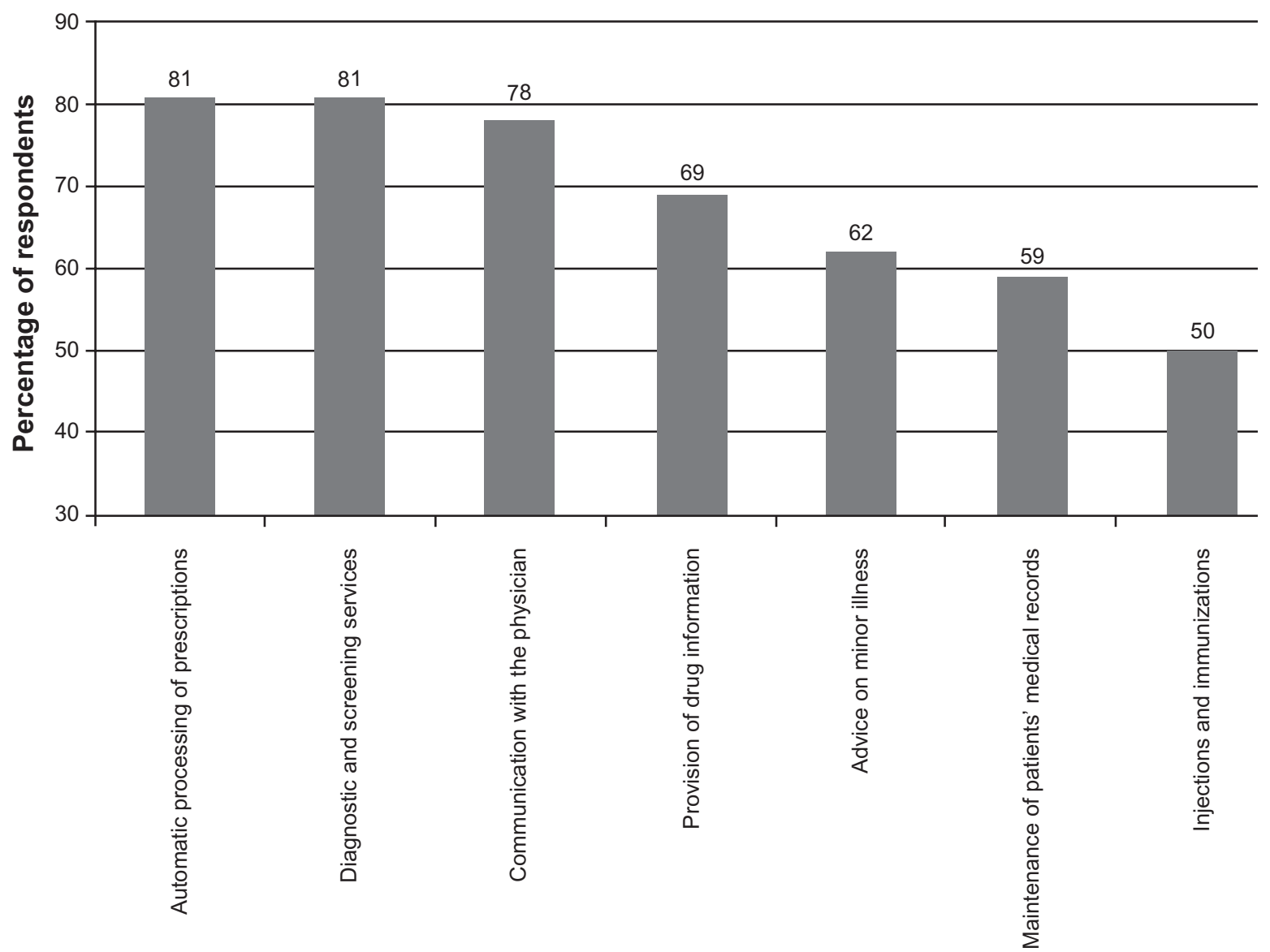

Figure 3 Services which participants would most like to see provided by community pharmacists.

between health and business matters, and 27\% indicated that pharmacists were more concerned with the business side of their work than with the health of their patients.

In case of any drug-related question or problem, the physician was perceived as the first person to contact by $50 \%$ of respondents; and the pharmacist, by $41 \%$. Family members and friends were cited by $9 \%$ of respondents.

Table 2 summarizes patient expectations about the community pharmacist's role. Most patients agreed that the community pharmacist should provide them with the directions of use of medications (93\%), answer their drug-related questions (88\%), check their prescriptions for accuracy (83\%), and advise them about the treatment of minor ailments (79\%); however, more than $70 \%$ of patients didn't expect the community pharmacist to monitor their health progress and to perform any health screening.

When asked about the reasons that would lead them to seek advice from their pharmacist before their physician, the majority of patients indicated minor health conditions ( $91 \%$ of respondents), short waiting time needed to see the pharmacist (78\%), lack of appointment required to visit the pharmacy (76\%), and high medication knowledge (62\%) of the pharmacist. Interestingly, only $9 \%$ of respondents stated that they would never seek the pharmacist's advice.

The top four community pharmacist qualities that most respondents desired included communication skills (100\% of respondents), medication knowledge (98\%), honesty and professionalism (97\%), and understanding of patients' concerns (93\%). Communication in the native language was an important quality for $72 \%$ of respondents.

Table 3 outlines patients' perceived barriers for asking the community pharmacist questions. The most common barriers included lack of privacy in the pharmacy $(50 \%$ of respondents) and a higher trust in physicians compared with pharmacists (45\%).

\section{Patient survey-respondent use of community pharmacy}

The majority of participants (52\%) reported visiting a pharmacy at least once per month (ie, daily, weekly, and monthly). 
The main reasons for visiting a community pharmacy are shown in Table 4 . The two primary stated reasons for visiting a pharmacy were to obtain over-the-counter medications (93\% of respondents) and prescription medications (83\%). Only $35 \%$ of surveyed patients reported visiting a pharmacy primarily to ask for pharmacist advice and only $23 \%$ stated primarily visiting the pharmacy to get general health information.

The main factors influencing the choice of any particular pharmacy are shown in Figure 2. The primary factor was the pharmacy location ( $90 \%$ of respondents), which included the proximity of a pharmacy to home, work, medical clinic, or hospital and the presence of a pharmacy in a shopping mall followed by provision of a good range of products and services (79\%) and convenient pharmacy working hours (76\%). The pharmacist's knowledge was considered as a primary factor by $66 \%$ of respondents.

\section{Patient survey-respondent views of, and satisfaction with, community pharmacy services currently provided in Qatar}

Table 5 shows the extent of agreement with positive statements regarding the public views of the community pharmacy services currently provided in Qatar. Forty-five percent of respondents agreed that they felt totally at ease about asking the pharmacist for advice. Only 37\% agreed that the pharmacist gave them enough time to discuss their problem and was knowledgeable enough and always ready to answer their questions. Nevertheless, when asked about their current level of satisfaction with the community pharmacy services in Qatar, 88\% stated that they are highly satisfied.

The study participants were also questioned as to what community pharmacy services they would most like to see in the future in Qatar. Participants' responses are summarized in Figure 3. The majority of respondents desired automatic processing of prescriptions, and diagnostic and screening services in addition to communication with the physician.

\section{Discussion}

This study was the first of its kind in Qatar to examine the general public's attitudes, views, and practices regarding community pharmacy services.

Overall, the study respondents had positive attitudes toward the community pharmacist in Qatar. Forty-five percent of respondents perceived a balance between business and health aspects of pharmacy practices, and only $27 \%$ viewed community pharmacists as being more concerned with business matters than health matters.
The majority of respondents were familiar with the different roles and responsibilities of the community pharmacist, with the exception of two pharmaceutical care key elements: monitoring patient drug therapy and performing health screening. More than $70 \%$ of respondents disagreed that the pharmacist was expected to monitor the patient's health progress to ensure safe and effective medication use and that the pharmacist was supposed to perform proper screening and monitoring for specific diseases. This shows the lack of public awareness of the different professional services that the community pharmacist is supposed to provide. This lack of awareness might be from a lack of any chance to evaluate, try, or even use these services since Qatar's pharmacists have not provided these services before. If the transition to pharmaceutical care is to occur successfully, Qatar's community pharmacists should make considerable efforts to raise public expectations about their professional role and must demonstrate the potential benefits of extending pharmacists' contributions to the medication use process beyond ensuring accurate dispensing and providing basic counseling.

Fifty percent of the study respondents rated the physician as their primary source of drug-related information. Furthermore, when asked about the barriers that would prevent them from asking the pharmacist drug-related questions, $45 \%$ of patients listed the higher trust in physicians compared with pharmacists as a barrier. The respondents who did not consider the pharmacist as their first choice to answer their drug-related questions may have had unsuccessful experiences in getting such information from pharmacists or may not be aware that the pharmacists are capable of answering their drug-related questions or may feel that pharmacists do not have the necessary expertise to offer this service. In addition, these results emphasize the traditional belief in the physician's capabilities and skills. This belief is maintained by Qatar's old health care system, which is governed by physicians. In light of these findings, Qatar's pharmacists should educate the public on their accessibility, clinical experience, and ability to offer drug informational services and should strive to have a better integration in Qatar's health care system.

It is interesting to note that the majority of patients desired communication skills, medication knowledge, honesty and professionalism, and understanding of patients' concerns rather than personal aspects (friendlessness and other characters) as favorite qualities of community pharmacists. Communication skills are important skills that community pharmacists should master. Whether counseling patients 
or communicating with other health care professionals, pharmacists use their communication skills daily. Effective pharmacist communication is essential to establish an ongoing pharmacist-patient relationship, and to improve medication use by patients. ${ }^{16}$ In addition to communication skills, to embrace the philosophy of pharmaceutical care and to ensure optimal patient outcomes, the pharmacist should have enough therapeutic experience and judgment and should be willing to address patients' needs and concerns.

Most study participants (91\%) said that they would seek the pharmacists' advice before the physicians in the case of a minor illness. In comparison, the majority of the public in Jordan (63\%) and in Northern Ireland (67\%) reported that they would not hesitate to ask the pharmacist for advice, especially if the condition was not serious enough to see a doctor. ${ }^{12,17}$ This is promising in terms of advancing the community pharmacist's role in Qatar. Community pharmacists in Qatar are ideally positioned to serve as a public health resource to diagnose and treat minor ailments. This can help free general practitioners' time to concentrate on more serious illnesses.

The majority of the public (52\%) visited the community pharmacy at least once a month. This correlates well with the frequency of community pharmacy visits cited in studies carried out in Jordan (67.4\%), Northern Ireland (67.7\%), Malta (70.8\%), and the United Kingdom (74.6\%). ${ }^{12,13,17,18}$

The percentage $(93 \%)$ reported in our study for patients visiting the community pharmacy to obtain over-the-counter medications was higher than that reported in Jordan (50.3\%), Malta (23.3\%), and the United Kingdom (11.3\%). ${ }^{12,13,18}$ This is explained by the high number of medications available over the counter in Qatar, despite their classification as prescription medications in other countries. ${ }^{19}$ Given the high potential for the misuse and abuse of these medications, Qatar's community pharmacists should have a primary responsibility in promoting the safe, proper, and effective use of medications by Qatar's public.

As has been reported in different parts of the world, the main reason for using any particular pharmacy in our study was pharmacy location. ${ }^{12,13,17,18,20-22}$

Several issues of concern related to current community pharmacy services in Qatar were raised in this study. Only $34 \%$ of respondents agreed that the pharmacist provided them with thorough medication counseling and encouraged them to ask questions when getting their prescription medications. This may indicate that Qatar's community pharmacists are dispensing prescription medications presuming that the patients are already well informed about their health conditions and about their medications. One of the important aspects of pharmaceutical care is counseling patients regarding their medications. Pharmacist-provided medication counseling is vital for improving medication use and achieving desired outcomes. Community pharmacists in several countries such as Canada and the United States are required to provide patient education when dispensing prescription medications. ${ }^{23,24}$ This is not true for Qatar.

Accessibility is one of the benefits that community pharmacies have over other health care settings. Qatar's community pharmacists are not using this benefit to their advantage by increasing their contact time with patients. Only $37 \%$ of respondents agreed that the pharmacist gave them enough time to discuss their problem and listened to them carefully. This can be attributable to two possible reasons: lack of personnel in the pharmacy and lack of time. The majority of Qatar's community pharmacies are staffed by only one pharmacist and one pharmacy technician at any particular shift. Lack of time is also perceived by Qatar's pharmacists as a barrier for the provision of cognitive services including breast cancer health promotion and smoking cessation counseling. ${ }^{25,26}$ Thus, in order for Qatar's pharmacists to spend enough time with their patients, more pharmacy technicians need to be hired and better delineation should exist between the role of pharmacy technicians and that of pharmacists. If pharmacists are less involved in medication dispensing, they will have more time for patient centered pharmacy activities.

The third issue that was raised in the study was privacy in the pharmacy. Only $35 \%$ of respondents agreed that privacy concerning prescriptions was maintained by the pharmacist. Furthermore, $50 \%$ stated that lack of privacy in the pharmacy was a barrier to seek the community pharmacist's help. This can be due to the lack of a private area for consultation in the majority of community pharmacies in Qatar as shown in a recent study completed by QU College of Pharmacy. ${ }^{27}$

The last issue was the pharmacist's knowledge and ability to answer questions. Only $37 \%$ of the public agreed that Qatar's pharmacists were knowledgeable enough and were always ready to answer questions. This can be related to several factors. The first factor is that Qatar's community pharmacists are coming from diverse pharmacy curricula. These curricula may not adequately prepare their graduates to take the role of pharmaceutical care providers. Another factor is that continuous pharmacy education was never offered to Qatar's community pharmacists until QU College of Pharmacy established the first national continuing professional pharmacy development (CPPD) 
program in 2008. To implement pharmaceutical care in community pharmacies in Qatar, efforts should be exerted to identify the educational needs of Qatar's community pharmacists. Accordingly, the QU College of Pharmacy CPPD program in collaboration with Qatar's Supreme Council of Health would design educational activities that address the community pharmacists' inadequate knowledge, competencies, and skills.

The study participants responded positively regarding new community pharmacy services. Interestingly, 81\% supported the introduction of diagnostic and screening services. These services are essential for the development of pharmaceutical care practice in community pharmacies in Qatar. With the aid of diagnostic blood monitoring devices, pharmacists would be able to offer disease management programs for patients suffering from diabetes, dyslipidemia, and other diseases. Many studies have demonstrated that these pharmacist-delivered programs can improve patient outcomes. $^{4}$

This study had several limitations. The survey instrument used in the study was not evaluated for its reliability in Qatar. However, many of the survey questions were designed based on a previous survey done and tested for reliability and validity in Saudi Arabia. Qatar is very close to Saudi Arabia geographically and in terms of population characteristics. Therefore, we do not believe that this limitation was a real barrier, especially as our study was a pilot study only and was exploratory in nature. In addition, due to the nature of the direct questioning method, collected information may differ to some extent from that obtained in, for example, a mail survey, where the respondents would have more time to answer any given question. Our study was also limited by its small sample size, which may not properly represent Qatar's population. The percentage of Qataris in the study participants was not representative of that in the general population. Furthermore, younger respondents and those with higher educational levels were overrepresented, and elderly patients were underrepresented. ${ }^{28}$ Thus, generalization of the study results to all Qatar's public should be made carefully.

\section{Conclusion}

This pilot study is the first known attempt to assess public attitudes toward the community pharmacist's role and to investigate the public's use and views of community pharmacy in Qatar. Despite its limitations, this pilot study still provided valuable data, on which further data can be built. The study suggested that the public has good attitudes and awareness of the roles and responsibilities of the community pharmacist, with the exception of monitoring patient drug therapy, performing health screening, and serving as a primary drug information resource. In addition, several issues of concern related to community pharmacy services in Qatar were raised in this study. These included: inadequate pharmacist-provided medication counseling, insufficient pharmacist-patient contact time, lack of privacy in the pharmacy, and unsatisfactory pharmacist knowledge level.

Therefore to improve community pharmacy practice and to successfully implement pharmaceutical care in community pharmacies in Qatar, efforts may be warranted to address identified issues and to promote the roles of the community pharmacist in monitoring drug therapy and in serving as a public drug information resource.

\section{Acknowledgment}

This publication was made possible by a QU undergraduate research grant.

\section{Disclosure}

The authors report no conflicts of interest in this work.

\section{References}

1. Wiedenmayer K, Summers RB, Mackie CA, Gous GA, Everard M. Developing pharmacy practice: a focus on patient care. Switzerland: World Health Organization; 2006.

2. Hepler CD, Strand LM. Opportunities and responsibilities in pharmaceutical care. Am J Hosp Pharm. 1990;47:533-543.

3. Cerulli J. The role of the community pharmacist in identifying, preventing, and resolving drug-related problems [article on the Internet]. January 26, 2002 [cited August 31, 2009]. http://www.medscape.com/ viewarticle/421293_print. Accessed April 29, 2011.

4. Posey LM. Proving that pharmaceutical care makes a difference in community pharmacy. J Am Pharm Assoc. 2003;43(2):136-139.

5. American Pharmacists Association. Principles of practice for pharmaceutical care [article on the Internet]. 2011 [cited August 31, 2011]. http://www.pharmacist.com/AM/Template.cfm?Section=Newsroom \&TEMPLATE $=/$ CM/HTMLDisplay.cfm\&CONTENTID $=2906$. Accessed April 29, 2011.

6. Schommer JC. Effects of interrole congruence on pharmacist-patient communication. J Health Commun. 1994;6:297-309.

7. Wikipedia.com. Qatar [article on the Internet]. May 31, 2010 [cited June 3, 2010]; http://en.wikipedia.org/wiki/Qatar. Accessed April 29, 2011.

8. Kheir N, Zaidan M, Younes H, El Hajj M, Wilbur K, Jewesson P. Pharmacy education and practice in 13 Middle Eastern countries. $\mathrm{Am}$ J Pharm Educ. 2008;72(6):1-13.

9. El Hajj M, Kheir AN, Al-Zaidan MB, Jewesson PJ. Pharmacist characteristics, medication use perceptions and professional satisfaction: a first national survey in the state of Qatar. J Healthcare Leadership. 2011;3:9-28.

10. Oparah AC, Kikanme LC. Consumer satisfaction with community pharmacies in Warri, Nigeria. Res Social Adm Pharm. 2006;2(4): 499-511.

11. The ratiopharm CFP Report on Pharmacy Services: Consumers' Perception of Pharmacy [online]. 2004 [cited June 19, 2011]. http:// www.ratiopharm.ca/pdf/cfp_eng.pdf. Accessed June19, 2011. 
12. Wazaify M, Younes A, Abu-Gharbieh E, Tahaineh L. Societal perspectives on the role of community pharmacists and over-the-counter drugs in Jordan. Pharm World Sci. 2008;30:884-889.

13. Cordina M, McElnay JC, Hughes CM. Social perceptions of community pharmaceutical services in Malta. J Clin Pharm Ther. 1998;23: 115-126.

14. Bawazir S. Consumer attitudes towards community pharmacy services in Saudi Arabia. Int J Pharm Pract. 2004;12:83-89.

15. Hargic O, Morrow N, Woodman C. Consumer perceptions of and attitudes to community pharmacy services. Pharm J. 1992;249:988-991.

16. McDonough RP, Bennettb MS. Improving communication skills of pharmacy students through effective precepting. Am J Pharm Educ. 2006;70(3):1-12.

17. McElnay JC, Nicholl AJ, Grainger Rousseau TJ. The role of the community pharmacist - a survey of public opinion in N. Ireland. Int J Pharm Pract. 1993;2:95-100.

18. Wazaify M, Shields E, Hughs CM, McElnay JC. Societal perspectives on over-the-counter (OTC) medicines. Fam Pract. 2005;22:170-176.

19. Wilbur K, El Salam S, Mohammadi I. Patient perceptions of pharmacist roles in guiding self-medication of over-the-counter therapy in Qatar. Patient Prefer Adherence. 2010;4:87-93.

20. Villako P, Raal A. A survey of Estonian consumer expectations from the pharmacy service and a comparison with the opinions of pharmacists. Pharm World Sci. 2007;29:546-550.

21. Cordina M, Safta V, Ciobanu A, Sautenkova N. An assessment of community pharmacists' attitudes towards professional practice in the Republic of Moldova. J Pharm Pract. 2008;6(1):1-8.
22. Stergachis A, Maine L, Brown L. The 2001 National Pharmacy Consumer Survey. J Am Pharm Assoc. 2002;42:568-576.

23. National Association of Pharmacy Regulatory Authorities. Model standards of practice for Canadian pharmacists. April 2003. Available from: http://cpe.pharmacy.dal.ca/Files/model_standards_of_practice_ for_Canadian_Pharmacists.pdf. Accessed April 29, 2011.

24. Omnibus Budget Reconciliation. Act of 1990, Pub. L. No. 101-508 and 4401, 104 stat 1388 (1990).

25. El Hajj M, Hamid Y. Community pharmacists in the state of Qatar: a survey of their interests and needs in relation to breast cancer health promotion. Int J Clin Pharm. 2010; DOI: 10.1007/s11096-0109449-y.

26. El Hajj M, Al-Qudah R, Al-Nakeeb R. Smoking cessation counseling in the state of Qatar: community and ambulatory pharmacists' attitudes, role perceptions and practices (Poster S 26). 2011 Dubai International Pharmaceuticals and Technologies Conference and Exhibition (DUPHAT); March 22-24, 2011; Dubai, United Arab Emirates.

27. Javed B, Ahmed H, Al Warad R. Assessing community pharmacy characteristics in Qatar. Qatar Health 2010 International Healthcare Congress and Exhibition; December 10-15, 2010; Doha, Qatar.

28. Results of the 2010 Census of Population, Housing and Establishments [online]. October 20, 2010. http://www.qix.gov.qa/ portal/page/portal/QIXPOC/Documents/QIX\%20Knowledge\%20 Base/Publication/Population\%20Statistics/Census\%20Publications/ Source_QSA/BookletofCensus_QSA_census_AE_2010.pdf. Accessed April 29, 2011. 


\section{Appendix I}

Study survey instrument (English version)

\section{Public Attitudes towards Community Pharmacy in Qatar: A pilot study \\ 1. Participants' demographics}

\section{Patient ID}

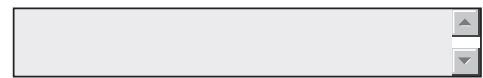

\section{Gender:}

$$
\begin{aligned}
& \text { Male } \\
& \text { Female }
\end{aligned}
$$

\section{How old are you?}
4. What is you marital status?
Married
Unmarried (single, widowed, divorced)

\section{Where do you come from?}
Qatar
Egypt
Jordan
Palestine
Lebanon
Sudan
Yemen
Syria
Philippines
India
Pakistan
Other (please specify)

6. What is your highest level of education?
Less than high school
High school
Technical degree or diploma
College degree or diploma
Undergraduate degree
Post-graduate degree

Appendix I (Continued) 


\section{Public Attitudes towards Community Pharmacy in Qatar: A pilot study}

\section{What is your occupation?}

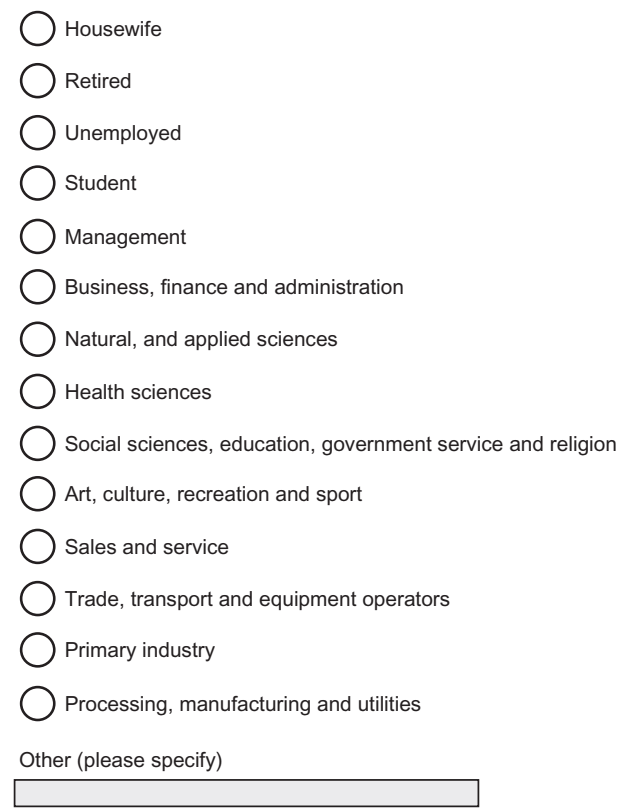

\section{What is your range of salary in QR?}
1. $<2000 Q R$
2. $2000-5000 Q R$
3. $5001-10,000 Q R$
4. $10,001-15,000 Q R$
5. $>15,000 \mathrm{QR}$

\section{Participants' attitudes and expectations about community}

pharmacy in Qatar
1. What is your image of the community pharmacist in Qatar? (Choose one answer)
I think that community pharmacists in Qatar:
Are primarily business people who are more concerned with making money than with the health of their patients
Are interested in both health and business matters, but tend to be more concerned with the business side of things than health matters
Have a good balance between health and business matters
Are more concerned with the health of patients than with the business side of their work
Are health professionals who know a lot about drugs but are cocerned about, and committed to, caring for the public

Appendix I (Continued) 
Public Attitudes towards Community Pharmacy in Qatar: A pilot study

2. What are your expectations about community pharmacists' role? I expect the community pharmacist to...

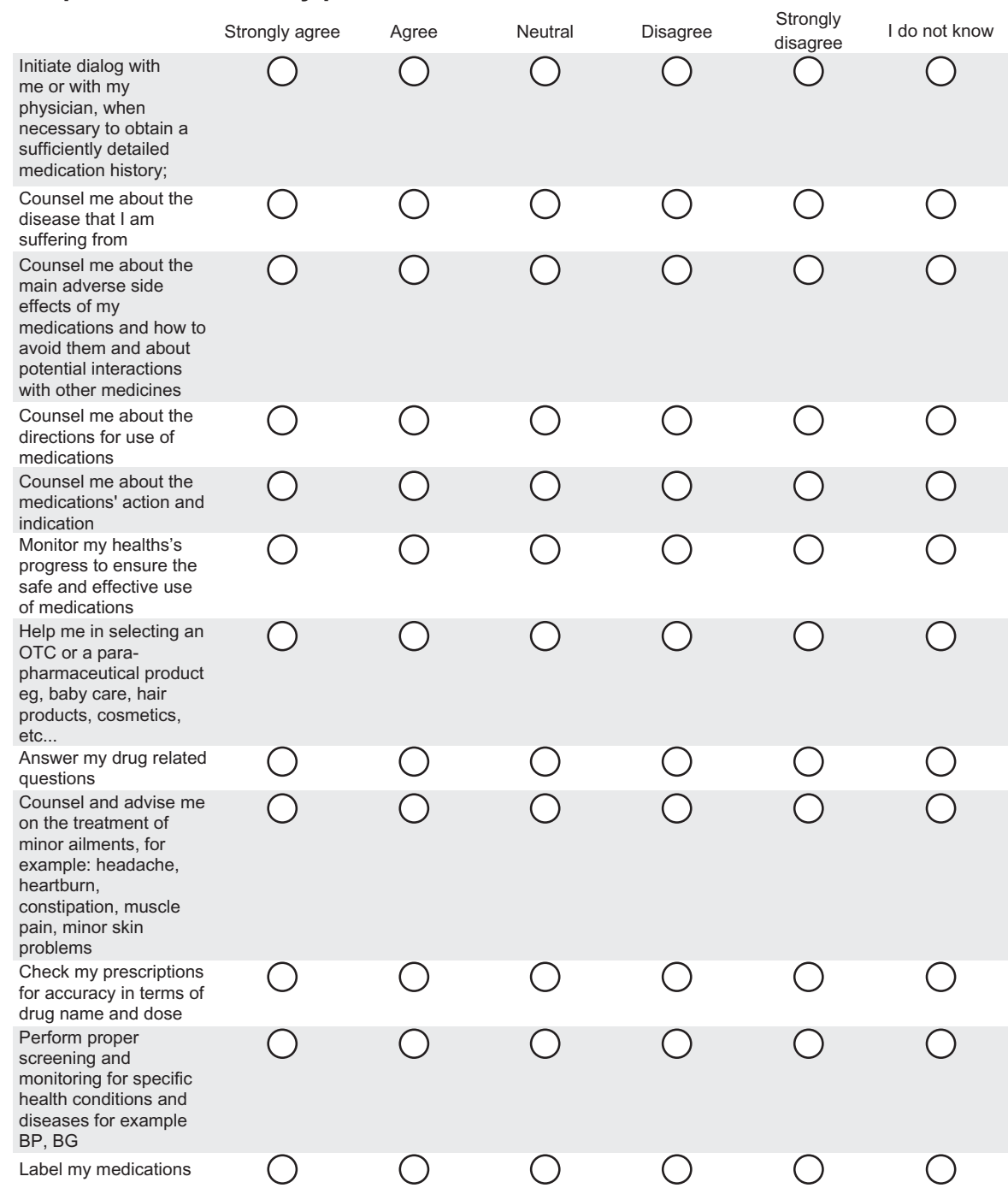

3. In case of any drug related question or problem, who is the first person you contact?

Physician

Pharmacist

Nurse

Family/friends

Other (please specify)

Appendix I (Continued) 
Public Attitudes towards Community Pharmacy in Qatar: A pilot study

4. What are the reasons for you to approach the pharmacist before the physician? (Choose all that apply)

I approach the pharmacist because of....

$\square$ Minor health problems, eg, heart burn, constipation, headache, muscle pain, minor skin problems etc...

$\square$ No appointment is needed to visit the pharmacy

$\square$ The pharmacy consultation is free of charge

$\square$ There is no waiting time required to see the pharmacist

$\square$ High pharmacist knowledge about medications (doses, side effects)

$\square$ I will never do it

Other (please specify)

5. What are the qualities of the pharmacist that you desire (Choose all that apply)

$\square$ Understanding of patients concerns

Knowledge about medications and about diseases

$\square$ Honesty and professionalism

Fastness of provision of services

Good communication skills

Willingness to offer advice and to answer any drug or disease related question

Communication in the native language

Others (please specify)

6. What barriers prevent you from asking any question to a pharmacist (Choose all that apply)

Fear or intimidation of asking the pharmacist (Don't want to ask stupid questions)

Lack of awareness of the ability of the parmacist to answer drug and disease related questions

$\square$ Lack of pharmacist's knowledge to answer drug and disease related questions

Busyness of the pharmacists

Rudeness of the pharmacists

$\square$ Lack of privacy in the pharmacy

$\square$ Unavailability of the pharmacists to answer my questions

$\square$ Doctors are trusted more than pharmacists (doctors always tell me everything I need to know about my medications)

Doctor will be offended if I ask the pharmacist

Others (please specify)

Appendix I (Continued) 
Public Attitudes towards Community Pharmacy in Qatar: A pilot study

3. Use of community pharmacy

1. what are the most common reasons for you to visit any community pharmacy? (Choose all that apply)

I visit any community pharmacy to:

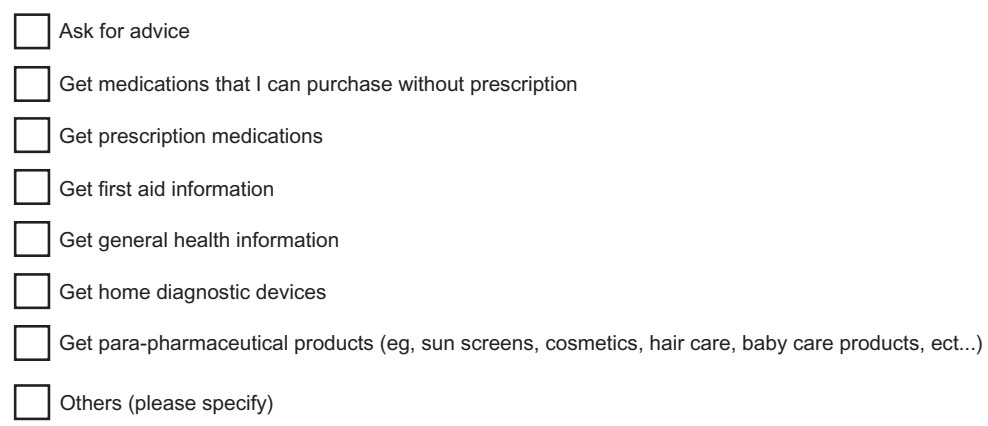

Appendix I (Continued) 
Public Attitudes towards Community Pharmacy in Qatar: A pilot study

3. How frequently do you visit community pharmacies?

Once or more per week

2-3 times per month

Every few months

Once per year

4. Consumers' satisfaction with community pharmacy services

1. What is you extent of agreement with the following: (strongly agree agree, neutral, disagree, strongly disagree, I do not know)

\begin{tabular}{|c|c|c|c|c|c|c|}
\hline & Strongly agree & Agree & Neutral & Disagree & $\begin{array}{l}\text { Strongly } \\
\text { disagree }\end{array}$ & I do not know \\
\hline \multicolumn{7}{|l|}{$\begin{array}{l}\text { When I am in the } \\
\text { pharmacy I feel totally } \\
\text { at ease about asking } \\
\text { the pharmacist for } \\
\text { advice }\end{array}$} \\
\hline \multicolumn{7}{|l|}{$\begin{array}{l}\text { When I am buying my } \\
\text { prescription } \\
\text { medications, the } \\
\text { pharmacist hands me } \\
\text { my prescriptions, } \\
\text { provides me with } \\
\text { through medication } \\
\text { counseling and } \\
\text { encourages me to ask } \\
\text { questions }\end{array}$} \\
\hline $\begin{array}{l}\text { When I am buying my } \\
\text { prescription } \\
\text { medications, privacy } \\
\text { concerning my } \\
\text { prescriptions is } \\
\text { maintained by the } \\
\text { pharmacist }\end{array}$ & & & & & & \\
\hline \multicolumn{7}{|l|}{$\begin{array}{l}\text { When I go to the } \\
\text { pharmacy with a } \\
\text { problem the } \\
\text { pharmacist gives me } \\
\text { enough time to discuss } \\
\text { my problem and listens } \\
\text { to me carefully }\end{array}$} \\
\hline $\begin{array}{l}\text { When I go to the } \\
\text { pharmacy to ask any } \\
\text { drug related question, } \\
\text { the pharmacist is } \\
\text { knowledgeable enough } \\
\text { and always ready to } \\
\text { answer my questions }\end{array}$ & & & & & & \\
\hline
\end{tabular}

Appendix I (Continued) 
Public Attitudes towards Community Pharmacy in Qatar: A pilot study

2. What is your current level of satisfaction with the community pharmacy services in Qatar?
Highly satisfied
Satisfied
Neutral
Dissatisfied
Highly dissatisfied

\section{What services would you like to see provided}

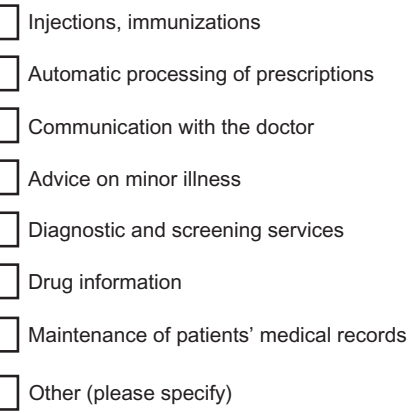

\section{Publish your work in this journal}

Patient Preference and Adherence is an international, peer-reviewed, open access journal focusing on the growing importance of patient preference and adherence throughout the therapeutic continuum. Patient satisfaction, acceptability, quality of life, compliance, persistence and their role in developing new therapeutic modalities and compounds to optimize clinical outcomes for existing disease states are major areas of interest. This journal has been accepted for indexing on PubMed Central. The manuscript management system is completely online and includes a very quick and fair peer-review system. Visit http://www.dovepress.com/ testimonials.php to read real quotes from published authors.

\footnotetext{
Submit your manuscript here: http://www.dovepress.com/patient-preference-and-adherence-journal
} 